\title{
Familial hypercholesterolaemia: Pilot study to identify children at risk
}

C J Taylor, S Olpin, J Rattenbury, A Whippey, C Lunt, N Beckles-Willson, J Higginbottom, R J Pollitt, J Bonham, L S Taitz

\begin{abstract}
Aims-To evaluate a more effective method of identifying children with familial hypercholesterolaemia by screening a population at high risk.

Methods-Domiciliary measurement of random cholesterol concentration was made in 200 children who were first or second degree relatives of subjects with premature onset coronary artery disease. Measurements were taken by a health visitor using a portable analyser.

Results-Twelve new cases of familial hypercholesterolaemia were identified during the first nine months of the study. Random cholesterol concentrations were within the normal range $(<5.2 \mathrm{mmol} / \mathrm{l})$ in $70.5 \%$ of samples tested. Forty two (21\%) of patients tested had a borderline cholesterol $(5 \cdot 2-5.9 \mathrm{mmol} / \mathrm{l})$ but $50 \%$ of these fell within the normal range when fasting capillary samples were analysed. Children with significant hypercholesterolaemia on random testing (concentrations of $>5.9 \mathrm{mmol} / \mathrm{l})(8.5 \%)$ also had fasting venous blood assayed for high density lipoprotein (HDL) cholesterol and tri-glyceride in the laboratory. Results indicated that $6.5 \%$ of patients screened were at high risk of cardiovascular disease (ratio of total: HDL cholesterol of $>4 \cdot 5$ ), and $1 \%$ had a moderately increased risk (ratio 3.5-4.5).

Conclusions-Children with familial hypercholesterolaemia can be identified from a selected "high risk" population by measuring random capillary cholesterol concentration.
\end{abstract}

(F Clin Pathol 1993:46:730-733)

Department of

Paediatrics,

University of Sheffield

C J Taylor

A Whippey

C Lunt

N Beckles-Willson

J Higginbottom

L S Taitz

Department of

Pathology, Sheffield

Children's Hospital

S Olpin

J Rattenbury

R J Pollitt

J Bonham

Correspondence to:

Dr C J Taylor, Department

of Paediatrics, Sheffield

Children's Hospital,

Sheffield S10 2TH.

Accepted for publication

17 February 1993

Familial hypercholesterolaemia is the commonest significant autosomal dominant disorder with a gene frequency of about 1 in $500 .{ }^{1}$ The condition causes accumulation of low density lipoprotein cholesterol in the plasma leading to premature atherosclerosis. An estimated $51 \%$ of male and $12 \%$ of female heterozygotes will sustain fatal or non-fatal coronary heart disease by the age of $50 . .^{2}$ There is good evidence that atheroma in these patients begins to form in early life, ${ }^{3}$ and because a reduction in cholesterol may be seen after treatment with a low fat diet, ${ }^{4}$ it seems prudent to screen for the condition and to introduce dietary modification as early as possible. Once someone in a family with familial hypercholesterolaemia has been identified, the case for screening these "at risk" families is strong because the likelihood of serious vascular disease is so high..$^{5-8}$

There are extensive published findings on various forms of screening for hypercholesterolaemia. Opinions differ as to whether a selective approach identifying families at "high risk" or a form of universal screening should be used.9 Screening initiatives have included neonatal screening, ${ }^{1011}$ using cord blood, ${ }^{12}$ or by integration with screening for phenylketonuria ${ }^{13}$ and blood testing at school entry. ${ }^{14}$ DNA technology is of limited value in screening for familial hypercholesterolaemia ${ }^{15}$ but may be of use in differentiating those hypercholesterolaemic subjects who have defective apo- $\beta-100 .{ }^{16}$

All universal systems of screening by blood cholesterol determination have the disadvantage that the overlap between the upper range of normal and the disease range leads to a high false positive rate. It would, therefore, be more effective to attempt to identify children from families at high risk of familial hypercholesterolaemia. ${ }^{17}{ }^{18} \mathrm{~A}$ programme based on screening individuals with premature atherosclerosis could identify most families at risk and allow the children and adolescents to be screened while reducing the likelihood of false positive results.

Calculations suggest there are at least 300 children in Sheffield with familial hypercholesterolaemia, yet at the inception of this study fewer than 10 cases were known to the paediatric services. Two of these families were referred to their general practitioners by the Coroner following the premature deaths of their fathers from coronary artery disease (Taitz LS, personal communication). An attempt was therefore made to identify and treat all children systematically within this population group by targeting such at risk families.

\section{Methods}

Individuals with premature atherosclerosis, defined as evidence of coronary artery disease (previous myocardial infarction or angina) in men under 50 years and women under 55 years were considered as index cases and their families approached by a health visitor through their general practitioners. A detailed family history was obtained and cases with hypercholesterolaemia associated with other conditions, such as renal disease, diabetes, and hypothyroidism, were excluded. Index 
cases were identified from hospital and general practitioner records, review of patients admitted to coronary care units, scrutiny of death certificates and referrals from adult lipid clinics.

Family trees were drawn up through three generations and all individuals under 16 years of age were entered into the study protocol (fig 1). Random capillary blood samples were screened in the home for total cholesterol using a portable reflectance photometer (Lipotrend, Boehringer Corporation Ltd). Fasting capillary cholesterol and triglyceride concentrations were assayed enzymatically by Reflotron (Boehringer Corporation Ltd). The performance of these analyses was maintained and all borderline results checked in the laboratory using a centrifugal analyser (Cobas Bio, Roche Diagnostics Ltd). Interbatch analytical imprecision was assessed using commercially available quality assurance material on a weekly basis. The Lipotrend photometer showed a coefficient of variation (CV) of $4.2 \%$ at a concentration of $4.4 \mathrm{mmol} / 1$; the Reflotron, a CV of $3.2 \%$ at a concentration of

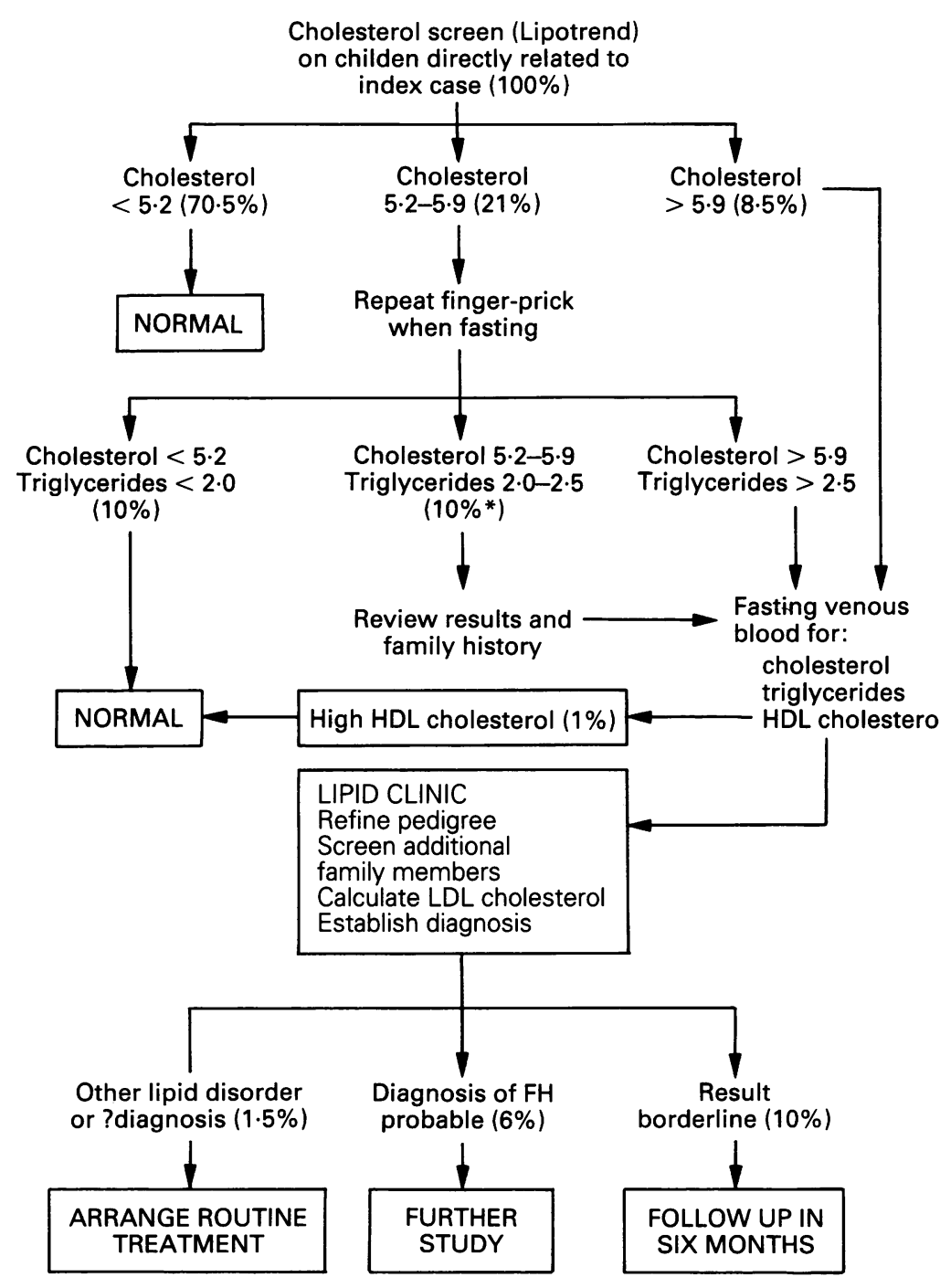

* Two children with cholesterol concentrations of $>5.2 \mathrm{mmol} / \mathrm{l}$ failed to attend for repeat sampling

Figure 1 Flow diagram of study protocol indicating percentage of patients falling into each diagnostic group.
$4.0 \mathrm{mmol} / \mathrm{l}$, and the Cobas Bio, a CV of $3.0 \%$ at a concentration of $2 \cdot 8 \mathrm{mmol} / \mathrm{l}$. The accuracy of the Reflotron was assessed by participation in a nationally organised external quality assurance scheme (Wolfson Research Laboratories extra laboratory assay survey); in all cases the returns were within $7 \%$ of the target value. The accuracy of the laboratory based analyser was monitored by participation in the national external quality assessment scheme for clinical chemistry. In all cases the returns were within $6 \%$ of their designated value. The non-laboratory methods showed good correlation with the laboratory based analyser: Lipotrend $v$ Cobas Bio, CV $r=0.89$; Reflotron $v$ Cobas Bio CV r $=0.99$.

Random cholesterol concentrations of $<5 \cdot 2$ $\mathrm{mmol} / \mathrm{l}$ were considered normal. Children with cholesterol concentrations of $>5.2$ $\mathrm{mmol} / \mathrm{l}$ were asked to attend the Children's Hospital where a further fasting capillary sample was obtained. Confirmed cholesterol values between $5 \cdot 2-5.9 \mathrm{mmol} / 1$ were considered outside the normal range but below that compatible with familial hypercholesterolaemia. All children in this group were seen, however, and dietary advice was given. Children with a random or fasting capillary cholesterol concentration of $>5.9 \mathrm{mmol} / 1$ had fasting venous blood assayed for total and HDL cholesterol and triglyceride values, using a centrifugal analyser (Cobas Bio, Roche Diagnostics). LDL cholesterol was calculated from the Friedewald equation. ${ }^{20}$

Children were considered to be at high risk of familial hypercholesterolaemia if the following criteria were met: a history of early coronary artery disease in a first or second degree relative, fasting total cholesterol of $>5.9 \mathrm{mmol} / \mathrm{l}$, HDL cholesterol of $<1.5$ $\mathrm{mmol} / \mathrm{l}$, LDL cholesterol of $>3.5 \mathrm{mmol} / 1$, normal fasting triglyceride values $(<2.3$ $\mathrm{mmol} / \mathrm{l})$. The risk of developing ischaemic heart disease in children with confirmed hypercholesterolaemia was calculated from the ratio of total:HDL cholesterol. ${ }^{21}$

\section{Results}

A total of 200 children, mean age 9.6 years, range 3-16.5 years, were identified from 120 families. The flow diagram (fig 1) shows how the study population were divided according to cholesterol concentration. Random cholesterol concentrations obtained using the Lipotrend analyser are shown in fig 2 . The mean random cholesterol for the whole study population was $4.7 \mathrm{mmol} / 1$ (range $2 \cdot 9-10 \cdot 7$ ), with $70.5 \%$ of these values falling within the normal range $(<5 \cdot 2 \mathrm{mmol} / \mathrm{l})$. A further fasting capillary sample was requested in the 42 $(21 \%)$ of patients with an initial cholesterol between 5.2 and $5.9 \mathrm{mmol} / \mathrm{l}$. This was analysed for cholesterol and triglyceride concentrations. No child showed an increase in cholesterol on retesting, but fasting cholesterol concentrations fell within the normal range $(<5.2 \mathrm{mmol} / \mathrm{l})$ in $50 \%$ of these repeat samples. Two children with a random cholesterol value of $\geqslant 5.2 \mathrm{mmol} / \mathrm{l}$ failed to attend 


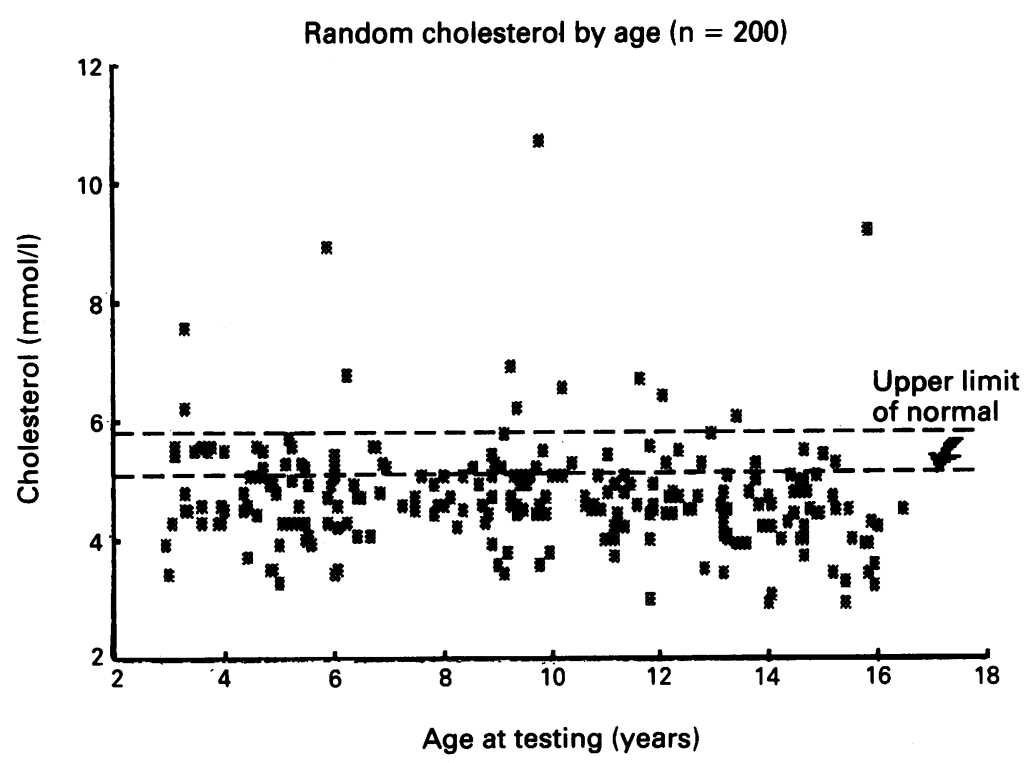

Figure 2 Distribution of random cholesterol concentrations (mmol/l) by age at testing for entire study population. Borderline results fall within dotted lines; values of $<5 \cdot 2$ are normal. low risk (ratio of <3.5). Twelve previously undiagnosed cases met the study criteria for familial hypercholesterolaemia; individual values for total, HDL, and LDL cholesterol are given in the table. Three children, who also had raised triglyceride concentrations, were felt likely to have familial combined hyperlipidaemia and remain under review at the time of writing.

\section{Discussion}

Although optimal strategies for identifying children with hypercholesterolaemia have not been established, the results of this pilot study indicate the value of domiciliary screening for familial hypercholesterolaemia in a selected population of children. Several authorities advocate testing of children with family histories of premature coronary artery disease. ${ }^{22} 28$ The usefulness of measuring cholesterol, however, either alone or with triglyceride, as a predictor of coronary heart disease in the general population has been questioned. ${ }^{23}$ Nevertheless, the range of cholesterol concentrations observed in our study compares well with data from cross-sectional population screening (fig 4) despite random (non-fasting) sampling.

The measurement of HDL cholesterol in screening could avoid the misclassification of some children because of an unusually high or low HDL cholesterol concentration. Between 5-15\% of children with normal LDL cholesterol concentrations have been identified as having hypercholesterolaemia because of increased HDL cholesterol concentrations. ${ }^{24} 25$ Only two children with initial cholesterol concentrations of $>5.9 \mathrm{mmol} / 1$ in this study had raised HDL values. Other workers have also reported little overlap with normal ranges for values above $6.8 \mathrm{mmol} / 1$ in close relatives of hypercholesterolaemic subjects. $^{2627}$ The measurement of apoprotein B and lipoprotein (a) may also improve the detection of "high risk" cases, ${ }^{28}$ but data are limited and the ahalyses more complex.

The proportion of children with familial hypercholesterolaemia not identified from the

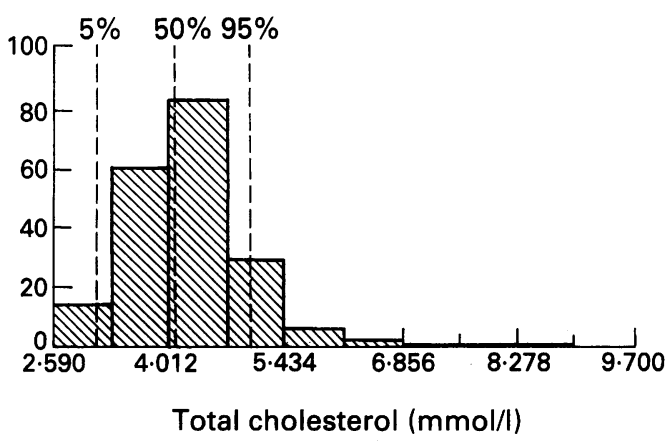

Figure 4 Comparison between study population and centile values for cholesterol concentrations in a "normal paediatric population", derived from Kwiterovich PO, et al. Effect of dietary treatment on the plasma of lipids, lipoprotein cholesterol, and LDL B protein in children with type II hyperlipoproteinemia. (Detection and Treatment of Lipid and Lipoprotein Disorders of Childhood. 1985:123-37 (Alan R Liss, Inc.)). 
family history is unclear from this study. Starc et al estimate that such selective testing may miss $12 \%$ of heterozygous children with familial hypercholesterolaemia ${ }^{29}$ yet their figures may overestimate the incidence compared with a normal population: data are derived from cases referred through primary care physicians. Few true cases of familial hypercholesterolaemia, however, are likely to be missed by screening for total cholesterol concentrations as random values may be expected to overestimate risk.

Hypercholesterolaemia can be treated by a combination of dietary ${ }^{30-32}$ and pharmacological methods, ${ }^{33-35}$ and both have been shown to lower the blood cholesterol concentration in children with familial hypercholesterolaemia. ${ }^{36}{ }^{37}$ Concern exists, however, over the long term effects of dietary restriction in growing children, ${ }^{38}$ the difficulty in adhering to the diet, possible non-compliance with drug regimens ${ }^{39}$ and a reluctance to single out otherwise healthy children. The case for preventive treatment in childhood currently rests on anecdotal evidence and analogy with the successful outcome for treated adults. ${ }^{40} 41$ The cost, compliance, and degree of psychological acceptance is unknown, as are the possible health benefits of such treatment provided over several decades. There is also no information on whether a hospital or community based programme would be the most effective method of provision. Until a properly controlled longitudinal study has been carried out to evaluate the various options these questions will not be resolved.

Patient identification is the first step in such a programme. Whole population screening yields a small return with an unacceptably high false positive rate, but the results of this study are sufficiently encouraging to warrant further investigation and assessment of at least some of these unknown factors before considering district-wide screening programmes of children "at risk".

We thank Drs TA Gray and ARW Forrest for their help and encouragement during this study.

1 Goldstein JL, Brown MS. Familial hypercholesterolaemia In: Stanbury JB, Wyngaarden JB, Fredrickson DS, Goldstein JL, Brown MS, eds. The metabolic basis of inherited disease. 5th edn. New York: McGraw-Hill, 1983:672-712.

2 Slack J. Risks of ischaemic heart disease in familial hyperlipidaemic states. Lancet 1969;ii:1380-2.

3 Spengel FA, Kaess B, Keller C, et al. Atherosclerosis of the carotid arteries in young patients with familial hypercholesterolaemia. Klin Wochenschr 1988;66:65-8.

4 Watts GF, Lewis B, Brunt JNH, et al. Effects on coronary artery disease of lipid-lowering diet, or diet plus cholestyramine, in the St Thomas' Atherosclerosis Regression Study (STARS). Lancet 1992;339:563-8.

5 Slack J, Leonard JV. Screening children for familial hypercholesterolaemia: The advantage of investigating highrisk families. Excerpta Medica 1979;470:400-5.

6 Heldenberg D, Tamir I, Levtov O, et al. Lipoprotein measurements-A necessity for precise assessment of measurements-A necessity for precise assessment of
risk in children from high risk families. Arch Dis Child risk in children

7 Leonard JV, Fosbrook AS, Lloyd JK, Wolff OH. Screening for familial hyper-beta-lipoproteinaemia in children in hospital. Arch Dis Child 1976;51:842-7.

8 American Academy of Pediatrics Committee on Nutrition. Indications for cholesterol testing in children. Pediatrics 1989;83:141-2.

9 Merz B. New studies fuel controversy over universal cholesterol screening during childhood. $\mathcal{F A M A}$ 1989;261:
814.

10 Andersen GE, Friis-Hansen B. Neonatal diagnosis of familial type II hyperlipoproteinemia. Pediatrics 1976;57: 214-20.

11 Wilcken DEL, Blades BEL. Dudman NDP. Neonatal screening for familial hypercholesterolaemia in the primary prevention of coronary artery disease. In: Therell BL. Jr, ed. Advances in neonatal screening. Amsterdam: Elsevier, 1987;337-40.

12 Boulton TJC, Craig JH, Hill G. Screening of cord blood low-density lipoprotein cholesterol in the diagnosis of familial hypercholesterolaemia; a study of 2000 infants. Acta Paediatr Scand 1979;68:363-70.

13 Wilcken DE, Blades BL, Dudman NP. A neonatal screening approach to the detection of familial hypercholesterolaemia and family-based coronary prevention. $f$ Inher Metab Dis 1988;11(Suppl 1):87-90.

14 Merz B. New studies fuel controversy over universal cholesterol screening during childhood. $¥ A M A$ 1989;261: 814.

15 Armston AE, Iversen SA, Burke JS. Diagnosis of familial hypercholesterolaemia using DNA probes for the low density lipoprotein (LDL) receptor gene. Ann Clin Biochem 1988;25:142-9.

16 Innerarity TL, Mahley RW, Weisgraber $\mathrm{KH}$, et al. Familial defective apoprotein B 100: a mutation of apoprotein B that causes hypercholesterolemia. $f$ Lipid Res 1990;31:1337-49.

17 Boulton TJ. The validity of screening for hypercholesterolaemia at different ages from 2 to 17. Aust NZ Med f laemia at differen.

18 Schieken RM. Identification of high risk relatives for coronary heart disease. $₹ \mathrm{Am}$ Coll Cardiol 1988;12:1110-3.

19 US Department of Health and Human Services. The Lipid Research Clinics Population Studies Data Book, 1: The Prevalence Study. Washington DC: US Government Printing Office; 1980 . NIH 801527.

20 Friedewald WT, Levy RI, Frederickson DS. Estimation of the concentration of low density lipoprotein cholesterol in plasma without use of the preparative ultracentrifuge. Clin Chem 1972;18:499-502.

21 Neil HAW, Mant D, Jones L, Morgan B, Mann JI. Lipid screening: Is it enough to measure total cholesterol conscreening: Is it enough to measure

22 Position statement of American Heart Association: diag nosis and treatment of primary hyperlipidemia in childhood. Circulation 1986;74:1181A-8A.

23 Neil HAW, Mant D, Jones L, Morgan B, Mann JI. Lipid screening: Is it enough to measure total cholesterol concentration? $B M \mathcal{F}$ 1990;301:584-7.

24 Kwiterovich OP Jr. Diagnosis and management of familial dyslipoproteinemia in children and adolescents. Pediat Clin North Am 1990;37:1489-523.

25 Garcia RE, Moodie DS. Lipoprotein profiles in hypercholesterolemic children. Am $¥$ Dis Child 1991;145:147-50.

26 Lloyd JK. Plasma lipoprotein disorders in childhood. $\mathrm{Br} f$ Hosp Med 1987;38:184-8.

27 Leonard JV, Whitelaw AGL. Wolff OH, Lloyd JK Diagnosing familial hypercholesterolaemia by measuring plasma cholesterol. BMF 1977;i:1566-8.

28 Thompson GR. What should be done about asymptomatic hypercholesterolaemia? $B M \mathcal{F}$ 1991;302:605-6.

29 Starc TJ, Belamarich PF, Shea S, et al. Family history fails to identify many children with severe hypercholesterolaemia. Am ₹ Dis Child 1991;145:61-4.

30 Fernandes J, Dijkhuis-Stoffelsma R, Groot PHE, et al. The effect of a virtually cholesterol free, high linoleic acid vegetarian diet on serum lipoproteins of children acid vegetarian diet on serum lipoproteins of children with familial hypercholesterola

31 Connor WE, Conner SL. Dietary treatment of familial hypercholesterolaemia. Arteriosclerosis 1989;9:191-205.

32 Kwiterovitch PO, Bachorik PS, Franklin FA, et al. Effect of dietary treatment on the plasma levels of lipids, lipoprotein cholesterol and LDL B proteins in children with type II hyperlipoproteinaemia. Prog Clin Biol Res 1985;188:123-37.

33 West R, Lloyd JK. Cholestyramine in hypercholesterolaemia. Lancet 1977;i:488-9.

34 Stein EA. Treatment of familial hypercholesterolaemia with drugs in children. Arteriosclerosis 1989;9:1145-51.

35 West R, Lloyd JK. Cholestyramine in hypercholesterolaemia. Lancet 1977; i:488-9.

36 Glueck CJ, Fallat R, Tsang R. Pediatric familial type II hyperlipoproteinemia: therapy with diet and cholestyramine resin. Pediatrics 1973;52:669-79.

37 Glueck CJ, Fallat RW, Mellies M, Tsang RC. Pediatric familial type II hyperlipoproteinemia: therapy with diet and colestipol resin. Pediatrics 1976;57:68-74.

38 Lifshitz F, Moses N. Growth failure associated with dietary treatment for hypercholesterolaemia. $\mathrm{Am} \mathcal{F}$ Dis Child 1989;143:537-42.

39 West RJ. Problems of long-term treatment in children with familial hypercholesterolaemia. Prog Clin Biol Res with familial hype

40 Krauss RM, Williams PT, Brensike J, et al. Intermediatedensity lipoproteins and progression of coronary artery
disease in hypercholesterolaemic men. Lancet 1987;ii: 62-5.

41 Brensike JF, Levy RI, Kelsey SF, et al. Effects of therapy with cholestyramine on progression of coronary arteriosclerosis: results of the NHLBI Type II Coronary Intervention Study. Circulation 1984;69:325-37. 